\title{
Fibroelastoma of the Mitral Valve as a Cause of Transient Ischemic Stroke
}

\author{
Alexandre Alessi, Roberto Gomes de Carvalho, Dalton Bertolin Précoma, Débora Fontoura, \\ Luciano Rodrigo Oliveira, José Zanis Neto, Marcello Zapparoli \\ Curitiba, PR - Brazil
}

\begin{abstract}
A 44-year-old woman had a transient ischemic stroke, fibroelastoma of the mitral valve being the source of the embolus. The patient evolved with neutropenia induced by ticlopidine after 10 days of treatment. We report the major clinical features, therapeutical options, and medicamentous toxicity resulting from the use of antiplatelet drugs.
\end{abstract}

Less than $5 \%$ of all cardiac tumors are primary tumors, which are, therefore, a rare entity; the remaining $95 \%$ are metastatic tumors to the heart ${ }^{1-3}$. Benign cardiac tumors account for $75 \%$ of primary cardiac tumors, of which the most common are myxomas usually originating in the left atrium. Papillary fibroelastomas are rare benign primary cardiac tumors, and for a long time their clinical significance was unknown. Currently, they are recognized as a cause of neurological and cardiac symptoms ${ }^{3-6}$.

This study aims to report peculiarities in the clinical findings of this entity in addition to reviewing current histologic, anatomicopathological, echocardiographic, and treatment concepts related to papilloma of the mitral valve.

\section{Case report}

A 44-year-old female sought neurological assistance on an emergency basis after an episode of transient ischemic stroke manifested predominantly as left facial hemiparesis of 15-minute duration. On physical examination at that time, she had no neurologic abnormalities any longer, and magnetic nuclear resonance imaging of the skull was normal. A cardiologic assessment was recommended to evaluate the cause of the transient ischemic stroke.

On the cardiologic assessment 1 week later, a search for the source of the embolism that caused the transient

Hospital Nossa Senhora das Graças - Curitiba

Mailing address: Alexandre Alessi - Rua Padre Agostinho, 1923/1701 - 80710-000

- Curitiba, PR, Brazil - e-mail: rgomesc@cardiol.br

English version by Stela Maris C. e Gandour ischemic stroke was started. The physical examination and the electrocardiography were normal, with no evidence of arterial hypertension, cardiac arrhythmia, or carotid arterial obstruction. The transthoracic echocardiography showed cardiac chambers of normal dimension, with no thrombi inside, normal left ventricular percentage systolic shortening and ejection fraction. The mitral valve showed a small mass on its anterior leaflet, and a normal and competent opening. The assessment was complemented with transesophageal echocardiography, in which a pediculate mass could be seen measuring $0.7 \mathrm{~cm} \times 0.7 \mathrm{~cm}$, with an area of $0.4 \mathrm{~cm}^{2}$ and circumference of $2.4 \mathrm{~cm}$ (figs. 1 and 2). The sequential investigation excluded the possibility of infectious endocarditis (no fever, normal hemogram, and 3 negative blood cultures), and the diagnosis of cardiac tumor was assumed as the possible embolic source. Ticlopidine was started at the dosage of $250 \mathrm{mg}$ twice a day, and surgical removal of the tumor was indicated, but refused by the patient at that time.

The patient had been healthy prior to this episode, totally asymptomatic, and was insecure in regard to the actual indication and benefit of an invasive procedure like a cardiac surgery with extracorporeal circulation and associated risks.

After 10 days of treatment with ticlopidine, started fe$\operatorname{ver}\left(40^{\circ} \mathrm{C}\right)$, intense asthenia, chills, and nocturnal sudoresis. Her hemogram showed 3,400 leukocytes with $23 \%$ of band neutrophils. In the first 24 hours of the infectious period, the patient's condition progressively worsened, and she was admitted to a general hospital with the diagnosis of internal otitis and bronchopneumonia. However, a hemogram with significant granulocytopenia ( 900 leukocytes and 12 band neutrophils) attracted attention. The treatment with an antibiotic was started associated with a colony-stimulating factor (Granulokineà). Because ticlopidine-induced granulocytopenia was suspected, this medication was suspended. The treatment proved effective after 14 days, with recovery from the infection and clinical improvement.

Based on medical recommendation, the patient used low-molecular-weight heparin (20 mg of enoxaparin) subcu- 


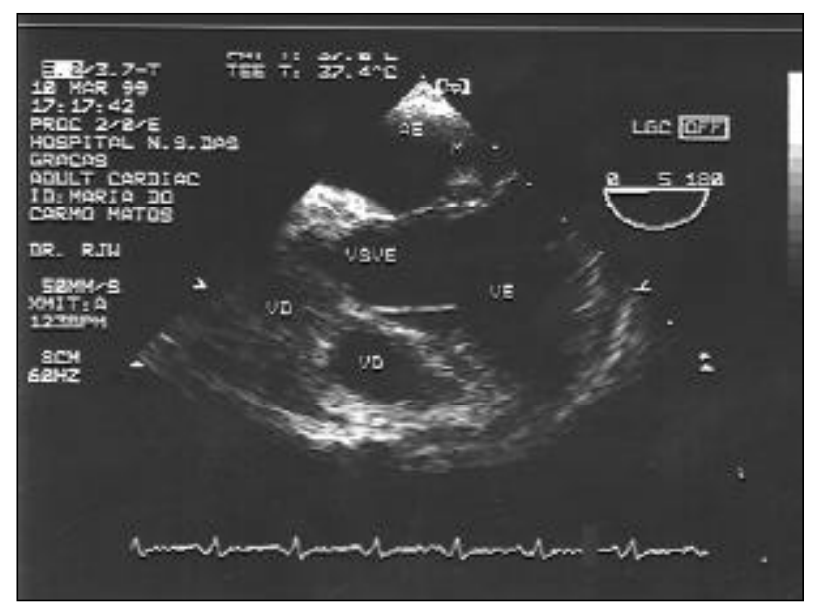

Fig. 1 - Transesophageal echocardiography showing fibroelastoma on the posterior leaflet of the mitral valve.

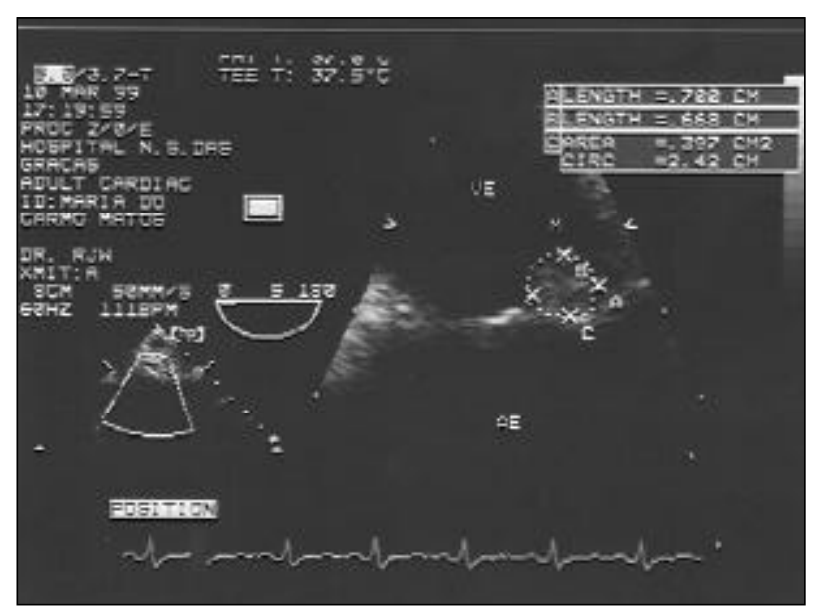

Fig. 2 - Zoom of the transesophageal echocardiography showing the dimensions of the fibroelastoma.

taneously at home for 2 weeks more. With total clinical recovery and partial improvement of the drug-induced granulocytopenia (4,800 leukocytes, 43\% segmented leukocytes, and $6 \%$ band leukocytes), the patient sought a large general hospital for cardiologic and hematologic reassessment.

In this new reassessment, the patient was apyretic and in good general condition. Three blood cultures were negative. Her hemogram still showed mild granulocytopenia, which gradually improved during her hospitalization. It is worth noting that from the beginning of the white cell disorder the patient never had a low platelet count. The new cardiologic tests performed were considered similar to those performed for investigating the source of the cardiac embolism. Surgery was indicated for removal of the benign cardiac tumor located in the mitral valve. By this time, the patient agreed to this type of treatment.

Surgery was performed with access through the anterolateral thoracotomy in the $4^{\text {th }}$ right intercostal space. Installation of the extracorporeal circulation circuit was performed through cannulation of the femoral artery and both cava veins with the membrane oxygenator and Bio-Pump.
The heart was protected with anterograde injection of hypothermic and blood solution. After incising the left atrium, a small mass on the atrial portion of the anterior leaflet of the mitral valve was identified and easily removed without destroying the valvar apparatus, therefore avoiding valvar repair. The heart was disconnected from the extracorporeal circulation circuit uneventfully. The patient was extubated in the recovery room and referred to the postoperative cardiac unit. Her postoperative evolution was excellent both from the cardiologic and hematologic points of view, and she was discharged from the hospital on the $4^{\text {th }}$ postoperative day.

The anatomicopathological study showed, on gross examination, a papillary fragment measuring $0.5 \times 0.5 \times 0.2 \mathrm{~cm}$, of white color, with a granular aspect, and smooth and elastic consistency (fig. 3). The microscopic study of the sections showed an anastomosing and branching papillary proliferation, similar to tendinous cords. The papillae were formed by axes of avascular tissue lined by a single layer of flat endothelial cells, compatible with papillary fibroadenoma of the mitral valve. These findings are different from those of the myxoma that may be located on cardiac valves; the presence of dense connective tissue, absence of vessels and of myxoid matrix, in addition to the presence of polygonal papillae in the papillary axes eliminate this possibility (fig. 4).

\section{Discussion}

Primary cardiac tumors are rare and correspond to less than $5 \%$ of all cardiac tumors; the remaining $95 \%$ are metastatic tumors to the heart ${ }^{1-3}$. Benign cardiac tumors correspond to $75 \%$ of the primary cardiac tumors, myxomas being the most common and usually originating in the left atrium (Table I) ${ }^{7}$.

The most frequent clinical findings are the following: asthenia, fever, weight loss, and embolic phenomena. Incidental or autopsy finding is, however, known to be more prevalent, as the diagnosis is not made because the clinical

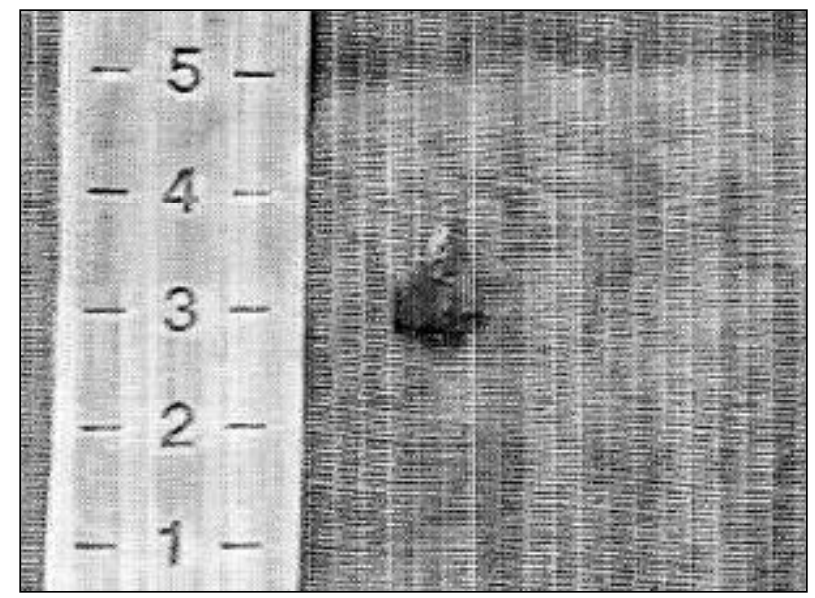

Fig. 3 - Gross examination of the papillary fragment with a granular appearance and smooth elastic consistency. 


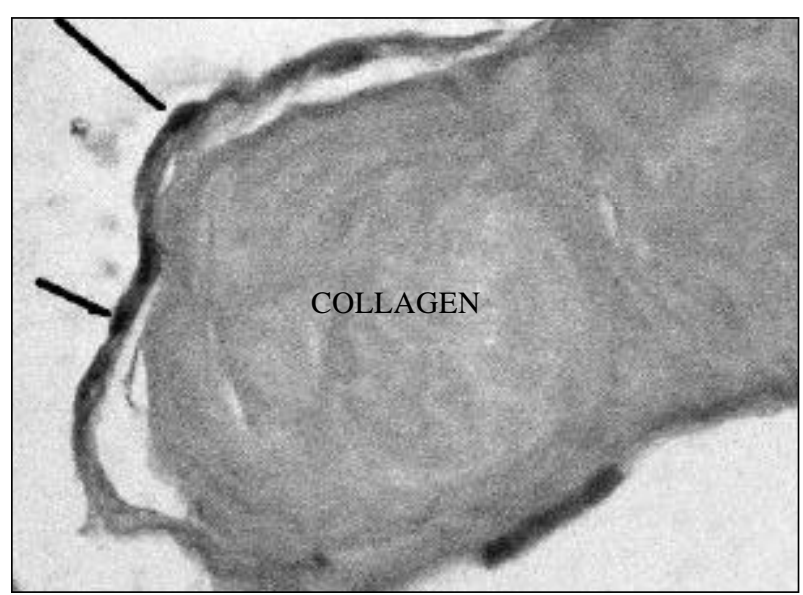

Fig. 4-Microscopy of the tumor mass showing connective tissue lined by a single layer of flat endothelial cells.

\begin{tabular}{|cc|}
\hline \multicolumn{2}{|c|}{ Table I - Primary cardiac tumors } \\
\hline Benign (75\% of the cases) & Myxoma \\
& Rhabdomyoma \\
& Fibroma \\
Lipoma \\
\\
Malign (25\% of the cases) & Atrioventricular node tumor \\
& Papillary fibroelastoma \\
& Hemangioma \\
& Angiosarcoma \\
& Rhabdomyosarcoma \\
& Fibrosarcoma \\
\hline
\end{tabular}

findings are not exuberant, and most patients remain asymptomatic ${ }^{8}$.

Papillary fibroelastomas are rare benign primary cardiac tumors. Their nomenclature becomes sometimes confusing because several terms (fibroma, cardiac papilloma, valvar papilloma, myxofibroma, fibroelastic hamartoma, and endocardiac papillary fibroma) have been used to name them; papillary fibroelastoma, however, is the most widely accepted name ${ }^{9,10}$. They are classified as endocardial tumors, and they may manifest as valvar insufficiency, coronary artery obstruction if located on the arterial surface of the aortic valve, or as an embolic complication ${ }^{2,5,6}$. Papillary fibroelastomas are characteristically small avascular solitary tumors with multiple spikelets, resembling a sea anemone, and adhered to the endocardium by a short pedicle ${ }^{7}$. Histologically, they are formed by a dense central axis of connective tissue surrounded by a layer of loose connective tissue lined by hyperplastic endothelial cells ${ }^{2,4,11}$. They may originate in any part of the endocardial surface, but their most common location is the valvar endocardium. In reality, papillary fibroelastomas are considered the most frequent primary cardiac tumor originating in the valvar endocardium ${ }^{11}$. The valvar distribution predominates in the left side of the heart, $29 \%$ of cases involving the aortic valve, $25 \%$ the mitral valve, $17 \%$ the tricuspid valve, and $13 \%$ the pulmonary valve ${ }^{1}$. In the case of involving the semilunar valves, the preferred location is the middle part of the valve, protruding into the atrial cavity ${ }^{1}$. Their dimensions range from 0.1 to $5.7 \mathrm{~cm}$, most of them having less than $1.5 \mathrm{~cm}^{3}$. These tumors have been reported in people of various ages, from 6-day neonates to 92 -year-old patients ${ }^{10}$. The destribution is equivalent in males and females. The first surgical description of a papillary fibroelastoma by Lichtenstein et $\mathrm{al}^{9}$ dates back to 1979 . Prior to echocardiography, they were uncommon findings of autopsy or cardiac surgeries. A recent review of the literature lists 198 cases of cardiac papillary fibroelastoma ${ }^{8}$. Surgical treatment has been recommended and, despite the benign tissular character, early diagnosis and treatment may prevent complications ${ }^{2,8,11}$.

Papillary fibroelastomas are loose excrescences typically located in cardiac valves. They may be single or multiple lesions occurring more frequently on the ventricular surfaces of semilunar valves and on the atrial surface of atrioventricular valves ${ }^{9,12}$. Nonvalvar locations are rare and include the mural and septal endocardium of the left or right ventricles, papillary muscles, tendinous cords, and the intimal layer of the coronary ostium. The tricuspid valve is most affected in children, and the mitral and aortic ones in adults ${ }^{12}$.

The major differential diagnosis should be made with Lambl's excrescences, which are acellular deposits lined by a single endothelial layer ${ }^{3,9}$. They are found on sites of endothelial lesions of the cardiac valves in more than $70 \%$ of the adults.

The clinical significance of muscle fibroelastomas remained unknown for a long time. Currently, they are recognized

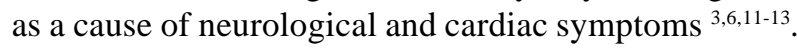
Embolization of a tumor fragment or of a thrombus on the tumor surface is not infrequent. A favorable situation for deposition of a niche of platelet aggregation is known to exist with posterior embolization of the fragments ${ }^{14}$. The neurological consequences of embolization include transient ischemic strokes, convulsions, syncopes, and infarcts in the following regions: brain, cerebellum, brainstem, spinal cord, and retina ${ }^{6}$. In a series of 71 operated upon fibroelastomas, 38 cases of embolization to the central nervous system were observed ${ }^{8}$. In reality, the embolic potential of the tumor results from fragmentation of the papillary spikelets of the tumor or even from thrombi formed by platelets and fibrin, which, frequently adhere to the uneven tumoral surface ${ }^{8,14}$. Hicks et al ${ }^{12}$, in a review of the echocardiographic evolution of patients with papillary fibroelastoma, showed a variety of clinical presentations, the neurological manifestation being the most frequent. In reality, an embolic cerebral stroke in a young individual with no evidence of cerebrovascular disease, particularly in the presence of sinus rhythm, should cause suspicion of a cardiac tumor, as well as infectious endocarditis and mitral valve prolapse ${ }^{14,15}$.

As the physical examination of a patient with papillary fibroelastoma is usually normal, a two-dimensional echocardiography is indicated in young patients with transient ischemic stroke or cerebral stroke, even in the absence of clinical or electrocardiographic cardiac disease ${ }^{16}$. Complementation of transthoracic echocardiography with transe- 
sophageal study increases diagnostic sensitivity ${ }^{10,14,17}$ This latter, with its high resolution, may distinguish the collagen center of the tumor from other cardiac structures, due to its shining echocardiographic appearance. This appearance helps to differentiate fibroelastomas from other intracardiac tumors, especially myxomas, but also from vegetations and mural thrombi. Currently, transthoracic echocardiography associated with a multiplane transesophageal study is the best examination to establish the diagnosis ${ }^{10,14}$.

Due to their potential of systemic embolization, these lesions should always be excised, despite their benign histological appearance and small dimension. Reports exist that even lesions of $3 \mathrm{~mm}$ may account for cerebral embolization, and should, therefore, be surgically removed in asymptomatic patients, who do not have surgical contraindication ${ }^{10}$. Despite their uncertain evolution, a review of a large case series ${ }^{8}$ showed that only 4 patients were free from symptoms when the fibroelastoma was discovered. Procedures preserving the valve are recommended in most cases ${ }^{8}$. Recurrence has not been reported; long-term follow-up, however, is recommended.
The last item to be discussed is the association with the possible ticlopidine-induced granulocytopenia, which our patient had. Important blood dyscrasias, such as thrombocytopenic purpura, aplastic anemia, and granulocytopenia, related to the use of this drug have been reported ${ }^{18-20}$. Even though the cause of bone marrow aggression remains uncertain, direct and immunological toxic mechanisms have been proposed ${ }^{18}$. Side effects associated with ticlopidine have been reported after implantation of coronary stents with a mean 4-week treatment with this drug, the higher frequency of events occurring after 14 days of treatment ${ }^{18}$. Drug withdrawal in selected cases is able to normalize the hematological disorder. Clopidogrel, an alternative to ticlopidine due to its similar antiplatelet activity, has also been shown to be safer in regard to its side effects ${ }^{21,22}$. A lower incidence of $0.26 \%$ of thrombocytopenia and $0.01 \%$ of neutropenia has been reported with clopidogrel use as compared with ticlopidine use, and a combined incidence of thrombocytopenia/neutropenia of $0.5 \%{ }^{21}$.

\section{References}

1. Mc Allister HA, Fenoglio JJ. Tumors of the cardiovascular system. In: Mc Allister HA, Fenoglio JJ, editors. Atlas of Tumor Pathology. Washington DC: Armed Forces Institute of Pathology, 1978: 20-5.

2. Ryan PE Jr, Obeid AI, Parker FB Jr. Primary cardiac valve tumors. J Heart Valve Dis 1995; 4: 222-6.

3. Salcedo EE, Cohen GI, White RD, Davison MB. Cardiac tumors: diagnosis and management. Curr Probl Cardiol 1992; 17: 73-137.

4. Cardiogenic brain embolism. Cerebral Embolism Task Force. Arch Neurol 1986; 43: 71-84.

5. Muir KW, McNeish I, Grosset DG, Metcalfe M. Visualization of cardiac emboli from mitral valve papillary fibroelastoma. Stroke 1996; 27: 1133-4

6. Graca A, Nunes R, Costeira A, Almeida J, Bastos P. Cardiac papillary fibroelastoma of a mitral valve chordae revealed by stroke. Rev Port Cardiol 1999; 18: 937-9.

7. Giuliani ER, Gersh BJ, McGoon MD, Hayes DL, Schaff HV. Mayo Clinic Pratice of Cardiology. Third ed. New York: Mosby, 1996.

8. Grinda JM, Couetil JP, Chauvaud S, et al. Cardiac valve papillary fibroelastoma: surgical excision for revealed or potential embolization. J Thorac Cardiovasc Surg 1999; 117: 106-10.

9. Lichtenstein HL, Lee JC, Stewart S. Papillary tumor of the heart: incidental finding at surgery. Hum Pathol 1979; 10: 473-5.

10. Shahian DM, Labib SB, Chang G. Cardiac papillary fibroelastoma. Ann Thorac Surg 1995; 59: 538-41.

11. Klarich KW, Enriquez-Sarano M, Gura GM, Edwards WD, Tajik AJ, Seward JB. Papillary fibroelastoma: echocardiographic characteristics for diagnosis and pathologic correlation. J Am Coll Cardiol 1997; 30: 784-90.

12. Hicks KA, Kovach JA, Frishberg DP, Wiley TM, Gurczak PB, Vernalis MN. Echocardiographic evaluation of papillary fibroelastoma: a case report and review of the literature. J Am Soc Echocardiogr 1996; 9: 353-60.
13. Mann J, Parker DJ. Papillary fibroelastoma of the mitral valve: a rare cause of transient neurological deficits. Br Heart J 1994; 71 : 6.

14. Daniel WG, Mugge A. Transesophageal echocardiography. N Engl J Med 1995; 332: 1268-79.

15. Grote J, Mugge A, Schfers HJ, Daniel WG, Lichtlen PR. Multiplane transoesophageal echocardiography detection of a papillary fibroelastoma of the aortic valve causing myocardial infarction. Eur Heart J 1995; 16: 426-9.

16. Giannesini C, Kubis N, N'Guyen A, Wassef M, Mikol J, Woimant F. Cardiac papillary fibroelastoma: A rare cause of ischemic stroke in the young. Cerebrovasc Dis 1999; 9: 45-9.

17. Etienne Y, Jobic Y, Houel JF, et al. Papillary fibroelastoma of the aortic valve with myocardial infarction: echocardiographic diagnosis and surgical excision. Am Heart J 1994; 127: 443-5.

18. Leon MB, Baim DS, Popma JJ, et al. A clinical trial comparing three antithrombotic-drug regimens after coronary-artery stenting. Stent Anticoagulation Restenosis Study Investigators. N Engl J Med 1998; 339: 1665-71.

19. Yeh SP, Hsueh EJ, Wu H, Wang YC. Ticlopidine-associated aplastic anemia. A case report and review of literature. Ann Hematol 1998; 76: 87-90.

20. Kao TW, Hung CC, Chen YC, Tien HF. Ticlopidine-induced aplastic anemia: report of three Chinese patients and review of the literature. Acta Haematol 1997; 98: 211-3.

21. A randomised, blinded, trial of clopidogrel versus aspirin in patients at risk of ischaemic events (CAPRIE). CAPRIE Steering Committee. Lancet 1996; 348 : 1329-39.

22. Bertrand ME, Rupprecht HJ, Urban P, Gershlick AH, Investigators of Doubleblind study of the safety of clopidogrel with and without a loading dose in combination with aspirin compared with ticlopidine in combination with aspirin after coronary stenting: the clopidogrel aspirin stent international cooperative study (CLASSICS) [In Process Citation]. Circulation 2000; 102: 624-9. 